\title{
The Epidemiology of Overuse Injuries in Ice Hockey: An Analysis from 29 Seasons in the Swedish Elite League
}

\author{
Johan Jonsson $^{1}$, Mattias Jonsson ${ }^{1}$ and Yelverton Tegner $^{2 *}$ \\ ${ }^{1}$ Västmanland hospital, Västmanlands sjukhus Västerås, Sweden \\ ${ }^{2}$ Department of Health Sciences, Division of Medical Sciences, Luleå University of Technology, Luleå, Sweden \\ *Corresponding author: Yelverton Tegner, Department of Health Sciences, Division of Medical Sciences, Luleå University of \\ Technology, Luleå, Sweden
}

\begin{abstract}
Background: An overuse injury is considered to be the result of iterated micro trauma or monotonous movements. Sports related to monotonous and repetitive movements have a high amount of overuse injuries. Ice hockey with its complexity of movements makes the player exposed to overuse injuries. The aim of this study was to analyze overuse injuries, and to study the long-term injury panorama. It is the first and essential step to obtain an injury-prevention method.
\end{abstract}

Study Design: Descriptive epidemiological study.

Method: Data from an elite ice hockey team was prospectively collected from 29 seasons. The definition of an overuse injury was a gradual onset injury caused by repeated micro trauma without a single identifiable event responsible for that injury and which resulted in absence from ice hockey.

Result: 315 overuse injuries were registered and accounted for $16.2 \%$ of all injury registrations. An overuse injury led on average to 1.8 missed games, 6.5 missed training sessions and 8.4 days of absence. August and September were the most injury months for an injury, with a total of $38.7 \%$ of the events. The most affected body region was the hip and groin, as $67.3 \%$ of all overuse injuries arose there. The second and third most affected body regions were the back and the knee respectively.

Conclusion: The present study reports that overuse injuries are a relevant problem. Primarily hip and groin are frequently affected. The beginning of the on-ice season has shown to be the most vulnerable period.

Keywords: Overuse Injuries; Ice Hockey; Hip; Groin; Back; Knee

\section{Introduction}

An overuse injury is considered to be the result of iterated micro trauma or monotonous movements which cannot be related to any particular event. The absence of a specific trauma often delays the diagnosis [1-4]. These types of injuries are often ignored due to the limited amount of pain and functional loss. The athlete often continues the exercise without sufficient time to heal the affected area and with the result of increased dysfunction and severe pain [3].

Sports related to monotonous and repetitive movements are typically cycling, running, swimming and cross-country skiing $[4,5]$. In technical sports, as well as in team sports, overuse injuries are common due to the considerable amount of training hours and monotonous repetitive movements, such as skating [1,6]. Among sports, overuse injuries most frequently affect the hip and groin, shoulder, elbow, wrist, back and knee. Typically, these types of injuries include tendinopathies, myalgia, stress fractures and bursitis [7-10]. Regardless the sport, tendon and muscle injuries are the dominating overuse injuries [5]. Ice hockey is a team sport with great popularity, especially in North America, Europe and Russia. The sport has full body contact and the skating in highspeed results in a high risk for injuries [11].

In ice hockey, the majority of the injuries originate from traumatic events $[7,12,13]$, although with its repetitive complexity 
of movements, make the players exposed to overuse injuries. This can be seen in goaltenders with the butterfly technique, defenders and forwards with flexion, adduction and external and internal rotation to the hip joint, all of which especially affect the hip and groin $[6,14-18]$.

Overuse injuries might be an underreported problem. According to B Clarsen et al. [1] the reason could be due to the inclusion criteria, which involve both reduction of physical function and time loss. In the systematic review the "Definition and Usage of the Term Overuse Injury" [3], K.G. Roos and S.W. Marshall recommends that the definition of an overuse injury should include a mechanism of gradual onset, and an underlying pathogenesis of repetitive micro trauma. In summary, there is no consensus in how the diagnostic criteria are specified in the literature. Several studies already exist that analyze traumatic events in ice hockey. To our knowledge, no published articles have had the epidemiology of overuse injuries as their main focus. The aim was to study the longterm injury panorama, the affected body regions and if there were any differences over and during seasons among overuse injuries in elite ice hockey players.

\section{Materials}

All players in a Swedish ice hockey team in the Swedish Hockey League (SHL) had all injuries and attendances in training and game registered. These records from the season 1984/85 to the season 2012/13 were included. In total 1942 injuries were reported among 267 players.

\section{Methods}

All injuries were diagnosed according to the ICD-10 standard. Overuse injuries, which occurred during on-ice season, August to April, were included.

For the first 15 seasons data were primarily recorded on paper and were later exported into the injury registration system "International Sport Injury System" (ISIS) [19]. From the season 2001 and onward, injuries were directly recorded into ISIS. All games, including pre-season and play-off, as well as every training session were recorded. When a player was out of play or practice or if he had to stop playing due to injury, the cause was documented. Consequently, only time-loss injuries were recorded into the system.

For calculations and analysis all data from ISIS was exported to Microsoft Excel 2010. The calculations of absence were based on 22 players per season, and a season was estimated to 273 days, first of August to the $30^{\text {th }}$ of April.

\section{Definition}

The definition of an overuse injury in this study was "a gradual onset injury caused by repeated micro trauma without a single identifiable event responsible for that injury" [4] and which resulted in absence from ice hockey. An overuse injury has a tendency to reappear. In our study, every injury, which gave absence, was counted. If the same type of injury at the same location reappeared the injury was counted as a relapsing injury.

\section{Ethics}

The study was ethically approved by the ethics committee in Umeå (registration number: 09/135M). Written consent was given from all participants.

\section{Results}

During the 29 seasons 267 players represented the club. There were 6496 training sessions, in average 224 per season and 1784 games, including pre-season, regular season and play-off, in average 61.5 games per season. In total, 1942 injuries were registered, and among them 141 first time overuse injuries and including relapsing there were 315 overuse injuries (16.2\% of all injuries) in 99 players. The number of first-time overuse injuries per season was 4.9 and 10.9 including relapsing injuries. The three consecutive seasons, $2002 / 03$ to $2004 / 05$, had a significantly higher rate of overuse injuries than other seasons and among them, the season 2003/04 had the highest number of overuse injuries with a total of 27 injuries (20 relapsing injuries). This season involved 279 training sessions and 69 games. The season 1996/97 had one documented injury, making it the season with least reported injuries.

\section{Body Regions}

Table 1: Total number of overuse injuries per region. Values expressed in number $(\mathrm{n})$ and percent $(\%)$ of affected region of all overuse injuries.

\begin{tabular}{|c|c|c|c|c|}
\hline Location & First-time & \% First-time & Relapsing & \% Relapsing \\
\hline Hip/groin & 67 & $47.5 \%$ & 109 & $62.6 \%$ \\
\hline Back & 22 & $15.6 \%$ & 27 & $15.5 \%$ \\
\hline Knee & 17 & $12.1 \%$ & 12 & $6.9 \%$ \\
\hline Abdomen & 8 & $5.7 \%$ & 2 & $1.1 \%$ \\
\hline Shoulder & 7 & $5.0 \%$ & 16 & $9.2 \%$ \\
\hline Head/Neck & 5 & $3.5 \%$ & 3 & $1.7 \%$ \\
\hline Foot & 4 & $2.8 \%$ & 1 & $0.6 \%$ \\
\hline Hand & 4 & $2.8 \%$ & 0 & $0.0 \%$ \\
\hline Thigh & 3 & $2.1 \%$ & 0 & $0.0 \%$ \\
\hline Elbow & 2 & $1.4 \%$ & 2 & $1.1 \%$ \\
\hline Thorax & 1 & $0.7 \%$ & 0 & $0.0 \%$ \\
\hline Leg & 1 & $0.7 \%$ & 1 & $0.6 \%$ \\
\hline Unspecified & 0 & $0.0 \%$ & 1 & $0.6 \%$ \\
\hline Total & 141 & & 174 & \\
\hline
\end{tabular}

The overuse injuries were classified into 13 different body regions, where 'hip and groin' was the most exposed in numbers and days of absence (Table 1). During the 29 seasons 'hip and groin' injuries caused 1390 (55.3\%) of the total 2512 days of absence. The number of missed games due to 'hip and groin' injuries were 253 
and 937 missed training sessions which were $48.1 \%$ respectively $47.9 \%$ of the total number of, games and training missed due to overuse injuries. The second most affected region for injuries was the back, resulting in 139 missed games and 426 missed training sessions. Knee injuries lead to 42 missed games and 172 missed training sessions. These three body regions; 'hip and groin', 'back' and 'knee', made up $80.6 \%$ of all overuse injuries.

\section{Absence}

The average player absence due to overuse injuries was $1.4 \%$ including both missed games and training sessions. $76.9 \%$ of the overuse absence was due to 'hip and groin'. 32 different ICD10 diagnoses were reported. The average age when an overuse injury was diagnosed for the first time was 27.0 years. The injuries resulted in an average of 1.8 missed games and 6.2 missed training sessions.

\section{Injuries Per Month}

Table 2: Overuse injuries per month. First time and relapsing injuries. Values expressed in numbers (n), and percent (\%).

\begin{tabular}{|c|c|c|c|c|}
\hline Month & First-time & \% First-time & Relapsing & \%Re-injury \\
\hline August & 37 & $26,2 \%$ & 35 & $20,1 \%$ \\
\hline September & 20 & $14,2 \%$ & 30 & $17,2 \%$ \\
\hline October & 14 & $9,9 \%$ & 27 & $15,5 \%$ \\
\hline November & 16 & $11,3 \%$ & 20 & $11,5 \%$ \\
\hline December & 12 & $8,5 \%$ & 21 & $12,1 \%$ \\
\hline January & 14 & $9,9 \%$ & 15 & $8,6 \%$ \\
\hline February & 18 & $12,8 \%$ & 16 & $9,2 \%$ \\
\hline March & 8 & $5,7 \%$ & 9 & $5,2 \%$ \\
\hline April & 2 & $1,4 \%$ & 1 & $0,6 \%$ \\
\hline
\end{tabular}

The two months with the overall highest amount of both first time and relapsing overuse injuries were August and September, with $72(22.9 \%)$ and $50(15.9 \%)$ respectively (Table 2). April was the month with the fewest reported overuse injuries with $3(1 \%)$.

Table 3: Number of overuse injuries compared to game and training hours. Values expressed in numbers (n).

\begin{tabular}{|c|c|c|}
\hline Month & Overuse injuries & Game and training hours \\
\hline August & 72 & 27776 \\
\hline September & 50 & 22649 \\
\hline October & 41 & 22330 \\
\hline November & 36 & 21555 \\
\hline December & 33 & 20803 \\
\hline January & 29 & 21396 \\
\hline February & 34 & 19846 \\
\hline March & 17 & 12601 \\
\hline April & 3 & 5150 \\
\hline
\end{tabular}

In 15 of the total 29 seasons, August was the month with the injury and 'game and training hours' maximum (Table 3), as well as the first month of ice-practice (Figure 1). Among the 13 body regions, nine body regions were affected in August. 47 (65.3\%) of overuse injuries in August were related to the 'hip and groin' region. The second and the third most affected body regions were the 'back' and the knee with nine (12.5\%) and four (5.6\%), respectively. The next three groups were 'abdomen', 'thigh', and 'head and neck'.

\section{The total number of all Overuse Injuries compared to Hip and Groin injuries throughout 29 Seasons}

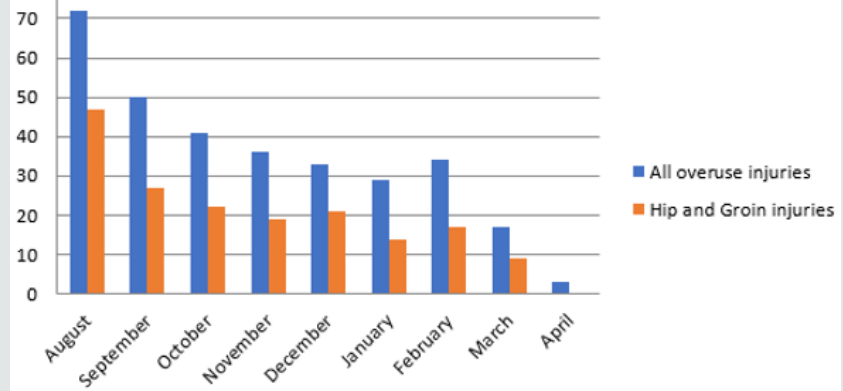

Figure 1: Comparison between all overuse injuries and hip and groin injuries per month. Values expressed in numbers (n).

\section{Discussion}

The primary finding of this epidemiological study was that 'hip and groin' injuries made up for the majority of the overuse injuries in ice hockey and were the dominant cause of absence. This study showed an almost linear correspondence between training and game hours and the number of overuse injuries. Overall, the beginning of the on-ice season had the highest amount of overuse injuries and highest number of training hours. August was the most exposed month for all overuse injuries, and particularly affecting the hip and groin.

Our intention was to analyze the long-term injury panorama of overuse injuries among elite ice hockey players; to understand the rate and seriousness, to analyze the amount of time the player was out of play, and to analyze changes during seasons are the first and essential steps to obtain injury-prevention and to develop a method for strategy against overuse injuries.

Location to 'Hip and groin' as well the total numbers of injuries are overrepresented in the beginning of the on-ice season. Reasons for this might be a too intense start of the on-ice season and the sudden change to skating. This shift might involve other types of muscles, making particularly the hip and groin region more prone to develop an overuse injury. Emery and Meeuwisse [16] pointed out that less ice hockey specific training during the summer months increases the risk to develop a groin injury compared with players who had more focus on ice hockey specific training. The same study indicated that players older than 25 years and players with a history of groin injuries had a higher risk to develop a new injury. In accordance with their study, this study confirms that players older than 25 years were more susceptible to an overuse injury. 
We were not able to analyze the off-ice training and we could not evaluate if the high number of overuse injuries was due to insufficient ice hockey specific or if the reason was the high number of training and game hours in the beginning of the on-ice season. Possibly, a more efficient transition from the pre-season practice to the start of the on-ice practice could reduce the high amount of overuse injuries in August. But this remains to be shown.

During the 29 seasons, 'hip and groin', 'back', and 'knee' were the most exposed body regions to overuse injuries. Ice hockey especially on an elite level requires for example substantial lower extremity and core muscular to be able to function well and prevent overuse injury. We were not able to evaluate weather bad muscular function was a factor for the amount of overuse injuries.

The yearly variation in numbers of injuries is difficult to explain to a full extent. Different coaches have different trainings resulting in different load on the players; the squad can be physically better fit during some years; some years the coaches have demanded that all players on ice should be able to participate in all parts of the training otherwise they should not be on ice at all and other years the coaches demanded that all players should be on ice if they could - irrespectively of their injury status. It seems as if the overuse injury once has appeared it is prone to reappear. The treatment of an overuse injury should therefore have two goals - first to heal the actual injury and secondly to prevent a re-injury.

The definition used was a gradual onset injury caused by repeated micro trauma without a single identifiable event responsible for that injury and which led to absence. As Roos and Marshall [3], pointed out in their study, there is no consensus in the definition of overuse injury. Therefore, it is difficult to make comparisons with other studies. In the current study, there were $315(16.2 \%)$ overuse injuries of a total of 1942 . The numbers correspond quite well to previous studies, that have reported that overuse injuries represented $15.4 \%, 15 \%$ and $8 \%$, respectively, of all injuries in ice hockey $[7,11,13]$. Adopting the suggestion by Clarsen et al. [1] study to include all physical problems, and not only the time loss criteria, would have led to even more injury registrations. All overuse injuries does not give absence, the players can sometimes still practice and play games but with a reduced ability.

In addition to our long-time follow up, the primary strength of this study was that the team has been followed by the same medical staff during all seasons and the treatment principles have been similar over the years. This therefore gives a large trust among the players and a good compliance to different treatment.

\section{Limitations}

A limitation with this epidemiological descriptive study, where the same team has been followed during the entire period, was that players were transferred to or from the team, or retired, and no follow up of these players has been done. Consequently, we cannot answer of what kind of injuries the player had before entering the team or respond to what happened when a player left. Occasionally, the same medical staff could be interpreted as a disadvantage, if the medical team does not improve its abilities and skills over the years. As mentioned before, overuse injuries are difficult to analyze, a player is generally willing to play with a small injury and sacrifice for the team, without informing the medical staff.

\section{Further Research}

In our research, we have established that injuries in the hip and groin region are the major problem. We encourage future research to analyze the type and intensity of the training to further explain the high amount of overuse injuries in the beginning of the season. More research is needed to investigate training methods, diet, and range of motion, as these are known to be important factors for avoiding overuse injuries.

\section{Conclusion}

Ice hockey is a sport with complex movements and with many directional changes, which requires great abdominal strength, and a balance between the thigh, hip and groin, and core musculature. The present study reports that overuse injuries are a relevant problem; primarily the hip and groin regions are frequently affected. The beginning of the on-ice season has shown to be the most vulnerable period.

\section{What are the New Findings?}

a) The majority of overuse injuries appear in the beginning of the on-ice season.

b) Hip and groin injuries represent more than half of the total number of overuse injuries.

c) There is almost a linear correspondence between game and training hours and overuse injuries.

\section{References}

1. Clarsen B, Myklebust G, Bahr R (2013) Development and validation of a new method for the registration of overuse injuries in sports injury epidemiology: The Oslo Sports Trauma Research Centre (OSTRC) overuse injury questionnaire. Br J Sports Med 47(8): 495-502.

2. Jacobson I, Tegner Y (2007) Injuries among Swedish female elite football players: A prospective population study. Scand J Med Sci Sports 17(1): 84-91.

3. Roos KG, Marshall SW (2014) Definition and usage of the term "overuse injury" in the US high school and collegiate sport epidemiology literature: A systematic review. Sports Med 44(3): 405-421.

4. Jingzhen Y, Tibbetts AS, Covassin T, Nayar S, Heiden E (2012) Epidemiology of Overuse and Acute Injuries Among Competitive Collegiate Athletes. Journal of Athletic Training 47(2): 198-204.

5. Ristolainen L, Heinonen A, Waller B, Kujala UM, Kettunen JA (2009) Gender differences in sport injury risk and types of injuries: A retrospective twelve-month study on cross-country skiers, swimmers, long-distance runners and soccer players. Journal of Sports Science and Medicine 8(3): 443-451. 
6. Philippon MJ, Weiss DR, Kuppersmith DA, Briggs KK, Hay CJ (2010) Arthroscopic labral repair and treatment of femoroacetabular impingement in professional hockey players. Am J Sports Med 38(1): 99-104.

7. Pettersson M, Lorentzon R (1993) Ice hockey injuries: A 4-year prospective study of a Swedish élite ice hockey team. Br J Sports Med 27(4): 251-254.

8. Baranto A, Hellström M, Cederlund CG, Nyman R, Swärd L (2009) Back pain and MRI changes in the thoraco-lumbar spine of top athletes in four different sports: A 15-year follow-up study. Knee Surg Sports Traumatol Arthrosc 17(9): 1125-1134.

9. Khan KM, Cook Jl, Bonar F, Harcourt P, Åstom M (1999) Histopathology of common tendinopathies. Sports Med 27(6): 393-408.

10. Hreljac A (2005) Etiology, prevention, and early intervention of overuse injuries in runners: A biomechanical perspective. Phys Med Rehabil Clin N Am 16(3): 651-667.

11. Flik K, Lyman S, Marx RG (2005) American Collegiate Men's Ice Hockey: An Analysis of Injuries. American Journal of Sports Medicine 33(2): 183 187.
12. Jorgensen U, Schmidt-Olsen S (1986) The epidemiology of ice hockey injuries. British Journal of Sports Medicine 20(1): 7-9.

13. Tegner Y, Lorentzon R (1981) Ice hockey injuries: incidence, nature and causes. Br J Sports Med 25(2): 87-89.

14. Braun P, Jensen S (2007) Hip pain - A focus on the sporting population. Austrailian Family Physician 36(6): 406-413.

15. McKay CD, Tufts RJ, Shaffer B, Meeuwisse WH (2014) The epidemiology of professional ice hockey injuries: A prospective report of six NHL seasons. Br J Sports Med 48(1): 57-62.

16. Emery CA, Meeuwisse WH (2001) Risk factors for groin injuries in hockey. American College of Sports Medicine 33(9): 1423-1433.

17. Stull JD, Philippon MJ, LaPrade RF (2011) "At-risk" positioning and hip biomechanics of the Peewee ice hockey sprint start. Am J Sports Med 39: 29S-35S.

18. Philippon MJ, Maxwell RB, Johnston TL, Schenker M, Briggs KK (2007) Clinical presentation of femoroacetabular impingement. Knee Surg Sports Traumatol Arthrosc 15(8): 1041-1047.

19. Tegner Y (2004) Injury registration for concussion registration. British Journal of Sports Medicine 38(5).

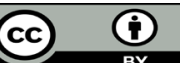

This work is licensed under Creative Commons Attribution 4.0 License

To Submit Your Article Click Here: Submit Article

DOI: $10.32474 /$ OSMOAJ.2019.02.000143

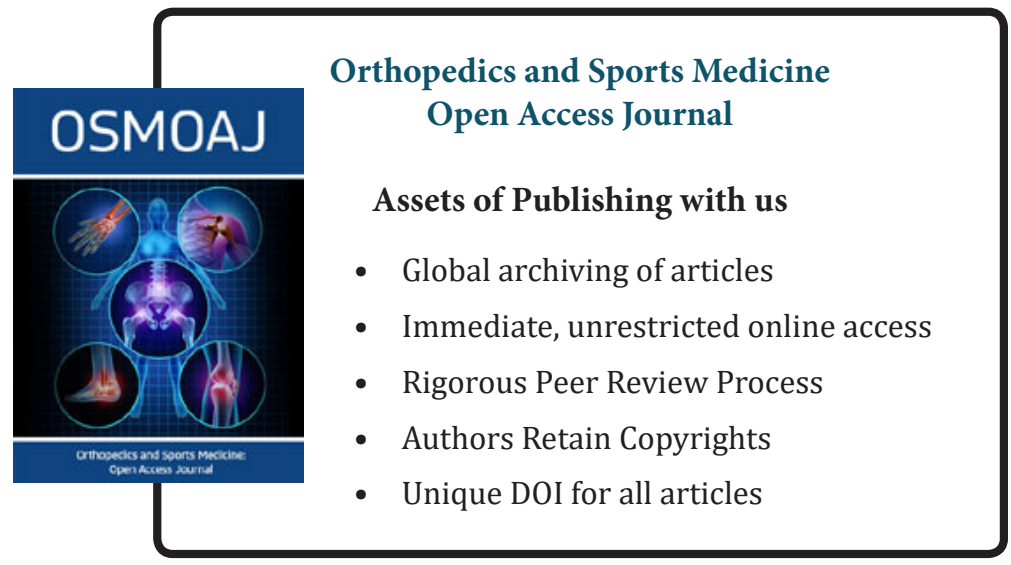

